\title{
Corrigendum
}

\section{Molecular genetic heterogeneity in undifferentiated endometrial carcinomas}

Juan M Rosa-Rosa, Susanna Leskelä, Eva Cristóbal-Lana, Almudena Santón, Ma Ángeles López-García, Gloria Muñoz, Belen Pérez-Mies, Michele Biscuola, Jaime Prat, Oliva E Esther, Robert A Soslow, Xavier Matias-Guiu and Jose Palacios

Modern Pathology (2016) 29, 1594; doi:10.1038/modpathol.2016.184

Correction to: Modern Pathology advance online publication, 29 July 2016; doi:10.1038/modpathol.2016.132
In this Article, the name of the tenth author is incorrect. The correct name is Esther Oliva. 